\title{
Coronavirus pushes education online
}

\author{
Litao Sun, Yongming Tang and Wei Zuo reflect on their experience of nationwide distance learning in China's \\ universities during the COVID-19 outbreak.
}

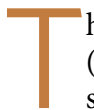
he coronavirus disease 2019 (COVID-19) pandemic has shown scant respect for manmade borders and it took just three months to bring the world to a standstill, proving how intimately connected we are as earthlings. Following the outbreak of COVID-19, China closed schools nationwide to prevent the spread of the virus. This led to the testing of distance education on an unprecedented scale. Here we give a first-hand experience of China's universities to provide quality distance education while battling the pandemic.

With all the campuses closed, universities swung into action to open 24,000 online courses, including 1,291 of China's 'national excellence courses' (competitive high-quality courses selected by the Ministry of Education) and 401 courses of virtual experimental simulations, provided on 22 platforms. This effort was coordinated by the Chinese Ministry of Education, which monitored the progress and quality of the online education services offered ${ }^{1}$.

To gain some insight into the effectiveness of such large-scale online education, we look at the results of a statistical survey conducted among 39,854 students at Southeast University in China. Around $50 \%$ of students believed that the planned teaching objectives were fully attained and $46 \%$ for objectives basically attained. Interestingly, most students agreed that in addition to maintaining continuity of education, teachers brought positive energy during classes to help them combat mental stress resulting from quarantine (Fig. 1). However, students were less enthusiastic when asked about 'focus and restraint' and gave it a relatively low score, clearly implying a greater need to improve self-discipline and concentration amid distractions such as unstable network speed, noisy environment and a lack of professional equipment. Students recommended combining recorded videos and live courses with more online interaction to mitigate the impact of unstable networks and increase students' participation. Providing a unified teaching platform with playback functions and appropriate amounts of homework, were also among the most frequently mentioned suggestions.

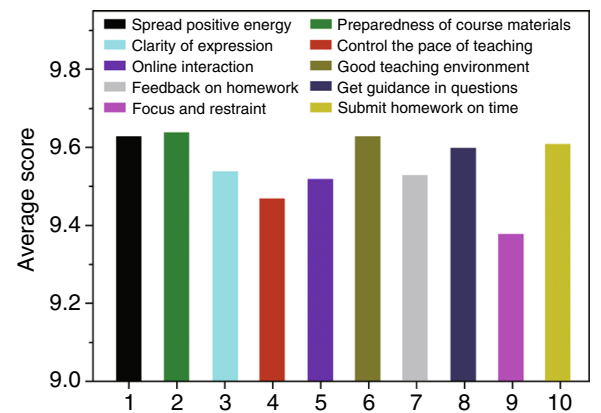

Fig. 1 | Statistics of responses to questionnaires collected among 39,854 students at Southeast University in China. Score (out of 10) on the quality of online teaching process.

This survey gave us the feedback that teachers have to adapt the pace of online teaching to take into account an environment completely different from that of a classroom. Currently, it is often common to simply duplicate online the content of traditional classroom lessons. However, in the absence of face-to-face communication, teachers need to put greater effort into preparing for online courses, innovating and designing lessons that will improve the attention span of the students. It also requires teachers to patiently turn students from passive recipients to engaged learners through interactive question and answer sessions, tests, presentations and open discussions. In the near future, we expect that the availability of $5 \mathrm{G}$ and artificial intelligence technology will break through the limitation of time and space and enable rapid replication and communication, optimal teaching resources, rich presentation tools and high-speed networks.

Besides online courses, graduate and final-year undergraduate students have to complete their thesis projects, which turns out to be even more challenging. With the exception of research directly related to pandemic prevention and control, all other activities that require laboratory data collection, field sampling or site investigation have been suspended. This not only means that experiments are delayed, but also that extra care must be taken to properly preserve sensitive samples and maintain large and expensive equipment. As such, special measures for lab maintenance in situations of forced prolonged inactivity, like the one caused by COVID-19, should be established and implemented quickly. Theoretical studies and social sciences research are less affected thanks to the availability of a large number of online libraries, archives and databases. Scientific calculations and simulations can be carried out using a home computer or supercomputers via online task submission. Literature search, data analysis and manuscript preparation are almost unaffected. Periodic online group meetings allow closer monitoring and support to students from their advisors. Online thesis defence is currently available, which, on the positive side, saves time and reduces costs for examiners to attend. Advisors have also been allowed to modify research project goals for final-year undergraduate students, setting tasks that can be carried out at home or at other available places.

Though COVID-19 has had a severe impact on normal educational progress, universities may take this unforeseen opportunity to detect deficiencies and speed up reform of online education through innovative course content, state-of-the-art technology and efficient management. We have to turn this emergency into an occasion to further promote international collaboration and share experiences, knowledge and resources to build global online education network.

Litao Sun (D) $\bowtie$, Yongming Tang and Wei Zuo Southeast Univrsity, Nanjing, China.

$凶_{e-m a i l: s l t @ s e u . e d u . c n}$

Published online: 27 April 2020

https://doi.org/10.1038/s41563-020-0678-8

Reference

1. Ministry of Education of the People's Republic of China http:// www.moe.gov.cn/srcsite/A08/s7056/202002/t20200205_418138. html (2020).

Acknowledgements

We acknowledge G. Zhang, B. Wang, J. Zheng, H. Ding, B. Jin, W. Sun, Q. Wang, L. Teng, Y. Xiong, C. Zhu, T. Xu and R. Bacsa for their support and insightful suggestions. 